\title{
USO DE ARTIGOS CIENTÍFICOS EM UMA DISCIPLINA DE FÍSICO-QUÍMICA
}

Gelson Ribeiro dos Santos, Luciana Passos Sá e Salete Linhares Queiroz*

Instituto de Química de São Carlos, Universidade de São Paulo, CP 780, 13560-970 São Carlos - SP, Brasil

Recebido em 7/4/05; aceito em 11/11/05; publicado na web em 5/5/06

\begin{abstract}
USING JOURNAL ARTICLES IN A PHYSICAL CHEMISTRY COURSE. This paper describes the use of primary chemistry literature in a fifth-semester physical chemistry course for undergraduate chemistry students. The main goal is to expose students to the primary literature of physical chemistry, demonstrating how they can benefit from using it. The assignment addresses issues in chemical education such as scientific writing, relating lecture material to the real world, and conducting literature searches. The student evaluation of this assignment, consisting of two surveys and one focus group, showed its usefulness. The details of the evaluation instruments and their results are provided. Out of 45 students enrolled in the course, $30(67 \%)$ students completed the assignment.
\end{abstract}

Keywords: graduate education; primary literature; physical chemistry.

\section{INTRODUÇÃO}

É notável a atenção dispensada por pesquisadores da área de Educação em Ciências a questões que envolvem a escrita e a leitura. Este interesse é evidenciado pelo acréscimo do número de publicações voltadas ao assunto em periódicos, tais como o Science Education e o Journal of Research in Science Teaching. Neste último, em 1994, foi publicada uma edição especial intitulada The Reading-Science Learning-Writing Connection, na qual figuraram artigos referentes tanto às relações entre ensino de ciências e leitura, quanto às relações entre ensino de ciências e produção escrita. A relevância deste assunto, em esfera nacional, também é considerável, sendo os encontros realizados sobre as relações entre ensino de ciências, leitura e literatura nos Congressos de Leitura, promovidos pela Associação de Leitura do Brasil, indicativos da existência de uma crescente dedicação à temática entre os pesquisadores brasileiros. As discussões e palestras realizadas nestes encontros culminaram em publicações como o Caderno Cedes $41^{1}$, intitulado Ensino da Ciência, Leitura e Literatura, e os livros Linguagens, Leituras e Ensino da Ciência ${ }^{2}$ e Textos de Palestras e Sessões Temáticas: III Encontro Linguagens, Leituras e Ensino da Ciência ${ }^{3}$.

Trabalhos particularmente relacionados ao tema da escrita e leitura no ensino superior de Química foram apresentados nesta revista ${ }^{4} \mathrm{e}$ apontaram o emprego de artigos científicos como recurso didático para o ensino-aprendizagem de Química. Uma investigação mais detalhada sobre o assunto mostra que as abordagens presentes na literatura voltadas à utilização de artigos científicos no ensino superior de ciências são variadas no que diz respeito às atividades propostas e às motivações que originam os estudos. Com relação às atividades propostas, estas envolvem um amplo leque de solicitações aos estudantes, que abarcam desde a redação de relatórios sobre as aulas práticas realizadas nos laboratórios de disciplinas específicas no formato exigido por uma determinada revista científica, como o Journal of American Chemical Society ${ }^{5}$, até a resolução de exercícios baseados em conteúdos e discussões presentes em artigos científicos ${ }^{6}$. Estudos de caso, usualmente associados aos cursos da área de humanas, são também propostos aos estudantes, sendo os casos elaborados com base em artigos científicos ${ }^{7}$. Com relação aos objetivos ambicionados com a rea-

*e-mail: salete@iqsc.usp.br lização das atividades acima descritas, e de outras similares, a literatura nos indica que incluem ensino e aprendizagem de conteúdos espe$\operatorname{cíficos}^{8}$, aperfeiçoamento das habilidades de comunicação oral e escrita em linguagem científica ${ }^{9}$, apresentação e discussão do processo de construção da ciência ${ }^{10}$ e estímulo a discussões sobre o planejamento de uma investigação e a interpretação de dados obtidos em experimentos $^{11}$.

Neste trabalho descrevemos uma proposta para o ensino superior de Química pautada na utilização de artigos científicos. Esta proposta exigiu a leitura de artigos científicos pelos alunos e a redação posterior de resumos sobre os conteúdos dos artigos. Ao final do semestre letivo, foram formados grupos de discussão e os envolvidos na experiência compartilharam os conhecimentos adquiridos e as impressões a respeito do processo. Um estudo cuidadoso das manifestações orais e escritas dos estudantes permitiu reunir, em categorias, as percepções enfatizadas nos depoimentos que mostram o papel creditado por eles à utilização do artigo científico com relação à aprendizagem em Química, à capacidade de expressão em linguagem escrita e de localização de referências bibliográficas primárias e secundárias. A apresentação destas percepções e o estabelecimento de analogias com experiências similares relatadas na literatura permitem-nos fazer aqui algumas considerações sobre a utilização de artigos científicos no ensino superior de Química.

\section{APLICAÇÃO DA PROPOSTA E COLETA DE DADOS}

A proposta para a utilização de artigos científicos foi aplicada junto aos alunos matriculados na disciplina Físico-Química I (SQF0309), do Instituto de Química de São Carlos, Universidade de São Paulo, por um dos autores deste artigo, em parceria com o professor responsável pela disciplina. Esta disciplina, carga horária de 4 créditos, é oferecida no quinto semestre do curso de Bacharelado em Química e no primeiro semestre de 2003 contava com 45 alunos matriculados, dos quais 30 participaram efetivamente de todas as atividades componentes da proposta, que era de caráter opcional e cujo cumprimento poderia acrescentar até um ponto na média final semestral do aluno.

A seleção dos artigos científicos que seriam distribuídos entre os alunos foi realizada pelo docente responsável pela disciplina, que considerou na sua escolha artigos cujos conteúdos guardassem relações 
Tabela 1. Alguns artigos científicos utilizados na disciplina de Físico-Química I

\begin{tabular}{|c|c|}
\hline ARTIGO E AUTOR(ES) & REVISTA, ANO, VOLUME, PÁGINA INICIAL \\
\hline $\begin{array}{l}\text { The reaction of serpines with proteinases involves } \\
\text { important enthalpy changes. } \\
\text { C. Boudier e J. G. Bieth }\end{array}$ & Biochemistry 2001, 40, 9962 \\
\hline $\begin{array}{l}\text { Kinetic investigations of a ketonization reaction } \\
\text { using reaction calorimetry. }\end{array}$ & Industrial \& Engineering Chemistry Research 199 \\
\hline $\begin{array}{l}\text { A.Crevatin, F. Mascarello, B. Leuthe, B. Minder e I. Kikic } \\
\text { van't Hoff and calorimetric enthalpies from isothermal titration } \\
\text { calorimetry. }\end{array}$ & Biochemistry 2001, 40, 1774 \\
\hline $\begin{array}{l}\text { J. B. Horn, D. Russel, E. A. Lewis e K. P. Murphy } \\
\text { The enthalpy of formation and C-H bond enthalpy of } \\
\text { hydrofullerene } \mathrm{C}_{60} \mathrm{H}_{36} \\
\text { S. M. Pimenova, S. V. Melkhanova, V. P. Kolesove A. B. Lobach }\end{array}$ & Journal of Physical Chemistry B 2002, 106, 2127 \\
\hline $\begin{array}{l}\text { Intramolecular interactions in diiodonaphthalenes. } \\
\text { I. Novak, H. Jiang e B. Kovac }\end{array}$ & Journal of Physical Chemistry A 2003, 107, 480 \\
\hline $\begin{array}{l}\text { Energetics of DNA intercalation reactions. } \\
J . \text { Ren, T. C. Jenkins e J. B. Chaires }\end{array}$ & Biochemistry 2001, 39, 8434 \\
\hline $\begin{array}{l}\text { Thermochemistry of gaseous OSiI, } \mathrm{OSiI}_{2}, \mathrm{SiI} \text {, and } \mathrm{SiI}_{2} . \\
\text { D. L. Hildenbrand, K. H. Lau, J.W. Baglio e C. W. Struck }\end{array}$ & Journal of Physical Chemistry A 2001, 105, 4114 \\
\hline G3(MP2) calculations of enthalpies of hydrogenation, & Journal of Physical Chemistry A 2002, 106, 1054 \\
\hline
\end{tabular}

isomerization, and formation of [3]-radialene and related compounds.

D. W. Rogers e F. J. McLafferty

The ionization energy of $\mathrm{CF}_{3}$ : when does entropy matter in gas-phase reactions?

K. K. Irikura

Effect of ancillary ligation on the relative bond disruption enthalpies of $\mathrm{Ru}-\mathrm{H}$ and $\mathrm{Ru}-\mathrm{Cl}$ bonds in $\mathrm{Cp}\left(\mathrm{PR}_{3}\right)_{2} \mathrm{RuX}$

$\left(\mathrm{PR}_{3}=\mathrm{PMe}_{3}, \mathrm{PMePh}_{2}, \mathrm{PPh}_{3} \mathrm{X}=\mathrm{H}, \mathrm{Cl}\right)$.

S. M. Freeman, F. R. Lemke, C. M. Haar, S. P. Nolan, e J. L. Petersen

Database of chemical reaction designed to achieve

thermodynamic consistency automatically.

P. M. May e K. Murray

Journal of the American Chemical Society 1999, 121, 7689

Organometallics 2000, 19, 4828

Journal of Chemical and Engineering Data 2001, 46, 1035 com a ementa da disciplina e que fossem recentes (ano de publicação no intervalo de 1999 a 2003). Todos os artigos selecionados, redigidos em língua inglesa, encontravam-se em periódicos específicos da área de Físico-Química ou de área correlatas, como Bioquímica e Engenharia Química. A Tabela 1 apresenta alguns destes artigos, cujos títulos podem ser facilmente relacionados aos conteúdos apresentados na ementa da disciplina, que é composta pelos tópicos gases reais; princípios da termodinâmica, conceito de energia e entropia: aplicações aos sistemas químicos; termoquímica; potenciais termodinâmicos (entalpia, energia livre), energia livre e equilíbrio; equilíbrio de fases (um componente), soluções ideais e diluídas; equilíbrio entre fases (dois a três componentes).

Na primeira semana do semestre letivo ocorreu a apresentação e explicação das atividades componentes da proposta aos alunos. Nesta ocasião, cada um deles recebeu a referência bibliográfica do artigo com o qual trabalharia durante o semestre e a incumbência de localizálo. A redação de um resumo sobre o artigo lido foi também solicitada. Este resumo foi apresentado no final do semestre letivo, quando os tópicos principais da disciplina de Físico-Química I já haviam sido ministrados. Os resumos deveriam procurar seguir as diretrizes apresentadas no Quadro I. Durante o semestre, dois questionários foram também aplicados com o propósito de fazer uma caracterização do alunado.

Na última etapa do projeto foram formados três grupos de discussão que se reuniram em horários distintos. Nestas ocasiões, cada um dos alunos foi convidado a apresentar oralmente, em um intervalo de 5 a 10 min, as principais idéias do texto lido, expressar opiniões a respeito do processo vivenciado, avaliar a proposta e sugerir modificações que poderiam conduzir ao seu aperfeiçoamento. Os trabalhos realizados nestes grupos foram gravados em fitas de áudio e vídeo.
Quadro 1. Diretrizes para a produção dos resumos na atividade desenvolvida na disciplina de Físico-Química I com artigos científicos

INSTRUÇÕES PARA A LEITURA E PREPARAÇÃO DOS RESUMOS SOBRE OS ARTIGOS CIENTÍFICOS

A seguir encontram-se apresentados aspectos importantes que devem ser considerados na leitura e redação dos resumos sobre os artigos científicos, que estaremos discutindo neste curso. $O$ trabalho de redação dos resumos é individual. $O$ resumo do artigo deve ser entregue até o dia em que iniciarmos a discussão em sala sobre o referido artigo. Na confecção do seu resumo, procure considerar os seguintes aspectos:

1. Por que a pesquisa descrita no artigo que você leu foi realizada? Qual a sua importância e quais benefícios pode trazer para a sociedade?

2. A quais conclusões chegaram os pesquisadores com base nos dados apresentados no artigo?

Após a redação do seu resumo, que deve ocupar pelo menos uma folha, faça uma avaliação final sobre o processo de confecção do mesmo. Esta avaliação deve levar em conta as suas impressões sobre a leitura do artigo (dificuldades, facilidades, necessidade de busca de informações/fontes bibliográficas para o entendimento das idéias do artigo, utilização de conceitos adquiridos na disciplina de Físico-Química I para a completa compreensão do texto etc).

No que diz respeito à carga horária dos encontros realizados, podemos afirmar que cada um dos três encontros iniciais, relacionados à apresentação da proposta, aplicação do Questionário 1 e aplicação do Questionário 2, ocorreu em um período de $1 \mathrm{~h}$. O último 
encontro, no qual foram formados os grupos de discussão, ocorreu em um período de $2 \mathrm{~h}$, para cada um dos três grupos formados.

Tendo em vista o caráter opcional da proposta, o que restringia a possibilidade de realização de atividades com os artigos científicos em sala de aula com todos os alunos matriculados em Físico-Química I, sua articulação com a disciplina limitou-se à realização da tarefa extraclasse anteriormente mencionada (leitura e interpretação dos artigos científicos e redação de um resumo) e à possibilidade de acréscimo de um ponto na média final semestral do aluno. Apenas 13 alunos alcançaram a pontuação máxima, os demais obtiveram um acréscimo de meio ponto na média. O critério adotado para este acréscimo foi estabelecido a partir de considerações sobre o grau de dificuldade que seria enfrentado pelos estudantes para cumprimento da tarefa extraclasse, em comparação às demais realizadas na disciplina (listas de exercícios, provas escritas etc). Na avaliação dos resumos considerou-se a clareza com que os estudantes expressaram o entendimento sobre os principais aspectos que motivaram a realização do trabalho científico e a importância deste trabalho para a sociedade; a relação existente entre o(s) problema(s) de pesquisa dos autores e as conclusões por eles apresentadas no final do artigo; conteúdos químicos em foco no artigo.

Considerando que a realização da tarefa solicitada aos estudantes durante a aplicação da proposta de ensino não se deu em sala de aula e que cada um deles pode ter adotado estratégias distintas para a execução, não se faz possível apresentar aqui uma estimativa do tempo gasto para o cumprimento da mesma. Esta particularidade da proposta também dificultou o registro das discussões ocorridas entre o professor e os alunos sobre questões relacionadas aos artigos científicos, uma vez que se davam de forma não premeditada e fora do horário normal de aula. A impossibilidade de gravações em áudio ou vídeo destes eventos e o fato de não termos solicitado ao professor depoimentos orais ou escritos sobre o andamento da proposta nos levou a decidir por não tomá-lo como sujeito da pesquisa.

Parte do material coletado durante o processo - questionários e filmagens das discussões sobre a atividade realizada - foi analisado considerando os aspectos resultantes da proposta que foram enfatizados nos depoimentos dos estudantes. Foram ainda investigadas as experiências anteriores de leitura de artigos científicos dos alunos, no que diz respeito à freqüência com que este tipo de leitura era realizada (tanto em disciplinas regulares do curso, quanto em atividades de iniciação científica). Os resumos produzidos pelos alunos foram analisados segundo a Análise de Discurso ${ }^{12}$ e o manuscrito contendo parte dos resultados desta análise encontra-se, como trabalho completo, nos Anais do V Encontro Nacional de Pesquisa em Educação em Ciências.

\section{RESULTADOS E DISCUSSÃO}

\section{Os alunos e as suas experiências anteriores com artigos científicos}

Os alunos responderam a dois questionários durante o desenvolvimento da proposta. O primeiro foi distribuído três semanas após a indicação dos artigos com os quais trabalhariam durante o semestre letivo. Este questionário (Questionário 1) foi aplicado com o intuito de conhecer suas experiências anteriores de leitura de artigos científicos e as impressões iniciais sobre o conteúdo dos artigos que haviam localizado. O Questionário 1, contendo a indicação das respostas apresentadas por 37 alunos, encontra-se no Quadro 2. As respostas permitiram concluir pela boa receptividade da proposta, à medida que apenas 6 alunos consideraram os artigos escolhidos como desinteressantes, e serviram como ponto de partida para a elaboração de um segundo questionário (Questionário 2), que objetivava confirmar informações e sanar dúvidas provenientes da resolução do Questionário 1. Trinta alunos responderam ao Questionário 2, apresentado no Quadro 3, e mencionaram a utilização de textos científicos em seis disciplinas ministradas no Instituto de Química de São Carlos. As disciplinas mencionadas com mais frequiência foram História da Química e Laboratório de Química Inorgânica I. As demais disciplinas receberam entre uma e quatro indicações pelos alunos. No entanto, através dos diálogos estabelecidos posteriormente nos grupos de discussão, os alunos concluíram que haviam se equivocado quanto à utilização de artigos científicos na disciplina de História da Química. Esta utilização, de fato, não ocorrera. Embora os artigos utilizados na disciplina fossem extraídos de revistas como o Journal of Chemical Education (um dos alunos citou o artigo de Barón ${ }^{13}$, With Clausius From Energy to Entropy, como exemplo) não apresentavam resultados originais de pesquisas e não continham as seções típicas de artigos desta natureza (Introdução, Materiais e Métodos, Resultados e Discussão e Conclusões) ${ }^{14}$.

Quadro 2. Questionário aplicado aos alunos durante a realização da atividade desenvolvida na disciplina de Físico-Química I contendo a indicação do número obtido de respostas para cada uma das questões

\begin{tabular}{|c|}
\hline QUESTIONÁRIO 1 \\
\hline $\begin{array}{l}1 \text { - Você já trabalhou anteriormente com artigos científicos como } \\
\text { recurso didático em alguma disciplina? } \square \text { Sim } \square \text { Não } \\
\text { Se respondeu Sim, indique o nome da disciplina. } \\
\text { - Número de respostas positivas }=35 \text { • Número de respostas } \\
\text { negativas = } \\
2 \text { - Você já teve oportunidade de ler artigos científicos em língua } \\
\text { inglesa? } \square \text { Sim } \square \text { Não } \\
\text { Se respondeu Sim, indique em qual ocasião. } \\
\text { - Número de respostas positivas = } 30 \text { • Número de respostas } \\
\text { negativas = } 7 \\
3 \text { - Depois de ter localizado o seu artigo, como você, a princípio, } \\
\text { o consideraria?Assinale com um X a(s) opção(ões) com a }(s) \\
\text { qual(is) você concorda: } \\
\square \text { Interessante, de um modo geral; } \\
\text { - Opção assinalada por } 20 \text { alunos } \\
\square \text { Interessante para o seu aprendizado na disciplina de Físico- } \\
\text { Química I; } \\
\text { - Opção assinalada por } 9 \text { alunos } \\
\square \text { Desinteressante, de um modo geral; } \\
\text { - Opção assinalada por } 1 \text { aluno } \\
\square \text { Desinteressante para o seu aprendizado na disciplina de Físico- } \\
\text { Química I; } \\
\text { - Opção assinalada por } 1 \text { aluno } \\
\square \text { Totalmente desinteressante. } \\
\text { - Opção assinalada por } 4 \text { alunos } \\
\text { OBS: dois alunos não assinalaram nenhuma das opções }\end{array}$ \\
\hline
\end{tabular}

Uma pergunta foi elaborada no Questionário 2 sobre a leitura de artigos científicos durante a realização da iniciação científica, uma vez que indicações sobre este tipo de utilização haviam surgido no Questionário 1, e uma outra sobre a habilidade de leitura e interpretação de texto em língua inglesa, uma vez que os artigos se encontravam neste idioma. As respostas apresentadas, conforme ilustra o Quadro 3, sugerem que a utilização de artigos científicos não se dá com frequiência em salas de aula ou laboratórios de ensino do curso de graduação em Química, do Instituto de Química de São Carlos. A grande maioria dos alunos teve contato com este tipo de recurso em uma única disciplina, Laboratório de Química Inorgânica I, e apenas 2 alunos disseram nunca ter utilizado artigos científicos em aulas 
anteriores. Em contrapartida, muitos alunos já haviam mantido contato com artigos desta natureza durante a realização de iniciação científica, o que não é surpreendente, como indicam trabalhos relatados na literatura sobre esta prática ${ }^{15,16}$. Assim, a atividade proposta, de uma maneira geral, não introduziu a linguagem científica ao universo dos alunos. Da mesma forma, a leitura em língua inglesa também não se apresentou como sendo uma atividade pouco familiar à maior parte dos alunos, que considerou a própria habilidade de leitura e interpretação de texto neste idioma entre boa e regular.

Quadro 3. Questionário aplicado aos alunos durante a realização da atividade desenvolvida na disciplina de Físico-Química I com artigos científicos contendo a indicação do número obtido de respostas para cada uma das questões

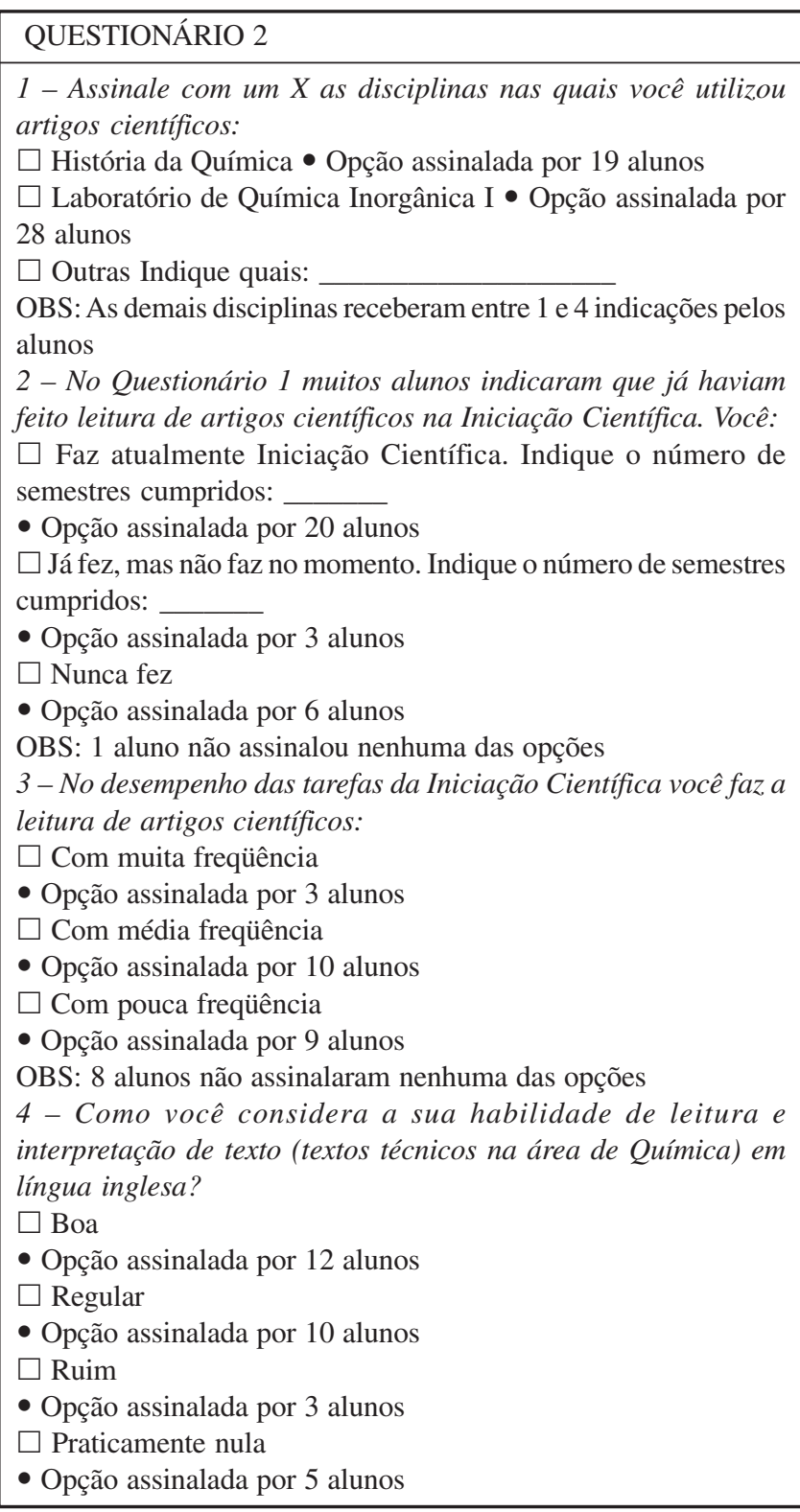

Os resultados da aplicação da proposta: as percepções dos alunos e as experiências relatadas na literatura

Os trabalhos realizados nos grupos de discussão foram conduzidos de tal maneira que cada aluno compartilhou oralmente com os colegas o conteúdo do artigo lido e apresentou suas percepções a respeito da atividade realizada. Conforme foi mencionado anterior- mente, a análise das manifestações orais e escritas dos estudantes permitiu reunir as percepções enfatizadas nos depoimentos em categorias que mostram o papel creditado por eles à utilização do artigo científico com relação à aprendizagem em Química, à capacidade de expressão em linguagem escrita e de localização de referências bibliográficas primárias e secundárias. A seguir serão apresentadas estas percepções, a partir das quais serão estabelecidas analogias com experiências similares relatadas na literatura.

\section{Os artigos científicos e a aprendizagem em Química}

Os pronunciamentos dos estudantes, com relação ao que extraíram da realização da experiência para o seu aprendizado em Química, não são homogêneos e incluem percepções distintas. A primeira delas, mencionada por um número significativo de alunos (52\%), sinaliza a atividade como tendo sido proveitosa para a aprendizagem de tópicos e assuntos ministrados na disciplina de Físico-Química I e, em alguns casos, ao aprendizado também, ou principalmente, de assuntos ministrados em outras disciplinas. Esta impressão foi colocada, via de regra, com as seguintes palavras:

(1) "Para o total entendimento da pesquisa foi necessário, e muito, os conhecimentos adquiridos em Físico-Química, principalmente aqueles relacionados a conceitos simples, como o de entalpia, pois sem ele o artigo ficaria mal interpretado e compreendido. Além disso, o artigo forneceu motivação para buscar novos conhecimentos e, principalmente, firmar conceitos para que sua total compreensão pudesse ser realizada".

(2) “A leitura e compreensão do artigo ajudou na aprendizagem do conteúdo visto na disciplina de Físico-Química I, além de ter facilitado a aprendizagem de outras disciplinas, como Inorgânica B".

(3) "No texto que eu li, foram necessários mais conceitos de química orgânica do que fisico-química para compreendê-lo. Aliás, os autores eram, em sua maioria, químicos orgânicos que apenas necessitaram de uma técnica que abrange o conceito de entalpia. O que quero dizer é que a maior preocupação dos autores foi entender melhor o conceito de aromaticidade, conceito esse visto em orgânica, do que o conceito de entalpia de formação, visto em físico-química".

A segunda impressão diz respeito à idéia do texto como eficiente agente facilitador do entendimento da aplicação da teoria ministrada em sala de aula e foi mencionada por 33\% dos alunos. Vários alunos buscaram ilustrar esta idéia correlacionando os termos "lousa" e "aplicação de conceitos":

(4) "No contexto geral foi bom. Deu para ver bastante coisa que tinha aprendido em sala de aula. Deu para ter uma idéia de como era um experimento em Físico-Química, porque tudo é muito teórico na lousa".

(5) "Eu achei interessante, achei legal a gente fazer isto porque é uma coisa diferente do que a gente vê na lousa, né? Aquilo que você vê, dá para você perceber que aplica para uma coisa que você talvez nem pensava que podia ser aplicada. Achei legal”.

(6) "A leitura do artigo facilitou a aprendizagem da matéria vista na disciplina de Físico-Química I, já que foi possível associar o que foi visto em sala com pesquisas interessantes, instigando a procura por outros artigos".

Apenas $10 \%$ dos alunos, além de reconhecerem o texto como ten- 
do funções acima explicitadas nos depoimentos dos colegas, sinalizaram que, a partir da leitura realizada, concepções e atitudes com relação ao conhecimento químico foram formadas ou repensadas:

(7) “Consegui relacionar o que estava aprendendo na matéria com o texto. Tem vários conceitos que foram usados lá, que são colocados aqui no artigo. Isto que eu achei importante. Eu consegui relacionar a capacidade calorífica, entalpia, entropia. Vários conceitos que a gente estava aprendendo, ele cita aqui. Que eu, na verdade, imaginava que não era usado aquilo lá para nada. Eu já havia olhado outros artigos relacionados à Físico-Química, mas só tinha conta, um monte de conta, o artigo inteiro era só conta. Não, não quero nunca um negócio desse para mim. Mas, na hora que eu vi este aqui que fala bastante da estrutura das moléculas, dos ligantes que eles usaram, eu achei interessante. Vamos dizer assim, o muro entre eu e a Físico-Química diminuiu um роисо. Está lá, ainda, mas diminuiu uт роисо”.

(8) "Foi interessante porque você começa a ver que Físico-Química não é só aquilo que está na lousa. E aquele monte de entalpia e entropia, que você não entende o que é aquilo. Como está funcionando aquilo num sistema, numa reação? Li o artigo, então comecei a pensar... Pô, na orgânica, que eu gosto um pouco mais (ainda mais o meu artigo que falava em reações orgânicas), você começa a ver que a Físico-Química está ali dentro também e que a gente tem que relacionar. A Química não é Físico-Química, Orgânica, Inorgânica, tudo separado. É tudo uma coisa só, está tudo relacionado. Então, por mais que eu não entenda as partes da Físico-Química (no artigo), as coisas são encaixadas. Eu consegui aproveitar um pouco do texto em relação a isto. Aquilo não é só Físico-Química. Há uma abrangência maior de conteúdo e acho que isto que foi favorável".

Uma última percepção, presente no depoimento de $16 \%$ dos alunos, aponta para a não eficiência do texto como agente facilitador da aprendizagem. Nestes depoimentos os alunos mencionam a falta de tempo disponível para realização de atividades desta natureza, dificuldade de leitura em idioma estrangeiro e descompasso entre os assuntos presentes no artigo e a matéria da vista em sala, como possíveis causadores desta falta de eficiência:

(9) "Não consigo associar nenhum tipo de correlação com a disciplina de físico-química, pois o artigo só trata de reações e equações da disciplina de inorgânica, a qual não tenho domínio do conteúdo. $O$ artigo lido não foi interessante para o aprendizado da disciplina. Proporcionou o contato com a literatura/linguagem científica, mas foi muito extenso e de difícil compreensão e de difícil interpretação, tomando, portanto, muito tempo para sua perfeita compreensão; sendo que a falta de tempo disponível de um aluno do curso de Química é um fator que influencia muito na qualidade dos trabalhos realizados".

(10) "O assunto tratado no artigo não foi estudado por mim anteriormente, visto que não foi comentado nas aulas de Físico-Química I ou em outras aulas. Porém, o estudo deste artigo me fez conhecer ou, pelo menos me deu uma noção de como são feitas pesquisas na área de termoquímica atualmente, e que a comparação de resultados via diferentes ferramentas é muito importante para comprovar a veracidade dos mesmos".

Possibilidades de aprendizado em Química, a partir da aplicação de atividades que exigem a leitura de artigos científicos, são mencionadas em alguns artigos. French ${ }^{17}$, ao descrever um curso de Química Orgânica Avançada no qual utilizou artigos científicos, frisou o fato da leitura dos artigos ter conduzido os estudantes a uma revisão e consolidação de conceitos básicos de Química Orgânica e a um entendimento da aplicação da Química (estudada nos cursos introdutórios no ensino superior) em trabalhos atuais sobre Síntese Orgânica. Garrat e Overtone ${ }^{11}$ também apresentaram o reforço no entendimento das teorias e conceitos embutidos nos artigos científicos sob análise, como um dos benefícios da estratégia por eles aplicada na Universidade de York. O estudo de tópicos de Bioquímica com o auxílio de artigos científicos, proposto por White ${ }^{6}$, foi executado através de resolução de problemas ("Problem Based Learning - PBL") e o levou a concluir que "estudantes do segundo ano de Química e formandos de Bioquímica já haviam se deparado com conceitos de estequiometria, equilíbrio, reações ácido-base, reações redox, solubilidade e espectroscopia e provavelmente demonstraram bom entendimento dos mesmos em disciplinas anteriormente cursadas. No entanto, os estudantes não costumam pensar sobre estes conceitos em situações reais ou correlacionados uns aos outros. $\mathrm{O}$ artigo deu oportunidade à revisão e correlação destes e de outros conceitos básicos de Química".

Análogas aos relatos de French ${ }^{17}$, Garrat e Overtone ${ }^{11}$ são algumas das percepções dos estudantes da disciplina de Físico-Química I, no que concerne à constatação da necessidade de revisão de conceitos básicos para o entendimento do conteúdo dos artigos na atividade por eles realizada (Citação 1). A compreensão da aplicação de conceitos básicos em situações reais, através da atividade realizada com os artigos científicos, também mencionada por French ${ }^{17}$, Garrat e Overtone ${ }^{11}$, foi igualmente apresentada em vários depoimentos dos estudantes. As colocações de White ${ }^{6}$, que ressaltaram a capacidade de correlação de conceitos químicos através da leitura dos artigos científicos, também vieram ao encontro de algumas das percepções dos estudantes (Citação 7). Assim, os relatos nos indicam que a revisão de conceitos básicos de Química, a correlação entre eles e o entendimento de suas possíveis aplicações, objetivos veementemente buscados no ensino de Química, podem ser contemplados através da aplicação de atividades em salas de aulas e laboratórios de ensino que privilegiem a discussão e a compreensão de artigos científicos.

\section{Os artigos científicos e o aprimoramento da linguagem escrita}

Durante a discussão em grupo $27 \%$ dos alunos falaram sobre as dificuldades por eles vivenciadas para a elaboração e escrita dos resumos. A proposta de leitura e escrita de um resumo sobre o artigo científico foi apontada como uma das poucas oportunidades por eles encontradas, até aquele momento, no curso de Química, para aperfeiçoarem esta habilidade. Os depoimentos seguintes falam sobre a preocupação dos estudantes quanto a este aspecto e procuram resgatar as experiências de escrita que identificam como emblemáticas no ensino superior:

(11) “Ajudou para escrever, para redigir. Mesmo para falar sou meio embaraçado, meio confuso. Foi legal nesta parte para eu escrever o texto. Eu escrevia uma frase, ficava olhando para ela e apagava. Não ficou legal. Eu mesmo me condenava. Escrevia de novo. Eu achei legal, me ajudou”.

(12) "Os textos, como são grandes, obrigam a gente a aprender a interpretar, buscar só o que interessa. Foi um trabalho mais elaborado, porque a gente teve que buscar, teve que pensar, teve que escrever, teve que colocar o que a gente entendeu. Os relatórios que a gente faz para a graduação são mais... A gente já sabe o que o professor quer ouvir, por exemplo".

(13) "Resumo, eu também tinha feito para a iniciação. Na graduação não tinha feito nada, porque os relatórios que a gente faz é mais 
parte experimental e conclusão. É meio sistemático: o procedimento, o que obteve e a conclusão".

(14) "Nas disciplinas, só na História da Química teve que redigir alguma coisa".

Menções sobre a dificuldade encontrada pelos estudantes de graduação em Química na comunicação dos seus conhecimentos são constantemente feitas em revistas especializadas de Educação em Ciências ${ }^{4}$. No caso particular da comunicação de idéias através da linguagem escrita verifica-se um agravamento considerável no grau destas dificuldades, conforme comprovam os depoimentos de alunos matriculados na disciplina de Físico-Química I. Como o campo da Química é potencialmente quantitativo, os currículos dos cursos de Química no ensino superior, de forma geral, enfatizam o desenvolvimento de habilidades quantitativas, como efetuação de cálculos e resolução de problemas, em prejuízo do desenvolvimento de habilidades qualitativas, como escrita. Assim, estratégias de ensino que trazem em seu bojo elementos que podem vir a promover o aperfeiçoamento da linguagem escrita dos estudantes são dignas de nota. Atividades que aliam esta característica à utilização de artigos científicos são descritas por Rossi ${ }^{10}$, Janick-Buckner ${ }^{18}$ e Tilstra ${ }^{5}$.

A proposta descrita por Rossi ${ }^{10}$, destinada a alunos matriculados nos últimos semestres do curso de graduação em Química, exigia a localização de artigo científico de um determinado autor, versando sobre um dado assunto. Nestes moldes, por ex., poderia ser solicitado ao aluno que localizasse e trabalhasse ao longo do período letivo com um artigo de E. J. Corey sobre a síntese de prostaglandinas. Ao final do processo, cabia a cada aluno escrever um resumo sobre as origens do campo de pesquisa apresentado no artigo e sobre as suas relações com outras pesquisas. Rossi ${ }^{10}$ apresentou o aperfeiçoamento das habilidades de escrita e de busca de fontes bibliográficas entre as vantagens resultantes desta estratégia. Janick-Buckner ${ }^{18}$ trabalhou com proposta semelhante à de Rossi ${ }^{10}$ em uma disciplina de Biologia Celular e, embora os alunos tenham reclamado do longo tempo necessário para elaboração e redação dos resumos, reconheceram que esta exigência os havia levado a estudar e compreender melhor o conteúdo dos artigos.

Na proposta descrita por Tilstra ${ }^{5}$, os artigos científicos são usados como modelos para preparação de relatórios de laboratório em disciplina de Química Geral. Esta proposta visava apresentar o formato e a linguagem presentes nestes artigos e ensinar os estudantes a desenvolver habilidades de expressão escrita, seguindo os padrões típicos desta linguagem. Cabe ressaltar a postura favorável dos alunos, tanto frente à proposta aplicada na disciplina de Físico-Química I, conforme ilustram os depoimentos anteriores, quanto frente às propostas descritas por Rossi ${ }^{10}$, Janick-Buckner ${ }^{18}$ e Tilstra ${ }^{5}$. Assim, a possibilidade de aprimoramento da habilidade de comunicação em linguagem escrita, quando oferecida aos estudantes em disciplinas no curso de graduação, parece vir ao encontro de uma necessidade que eles enfaticamente reconhecem que precisa ser suprida.

\section{Os artigos científicos e a localização de referências bibliográficas}

Os depoimentos dos estudantes sobre os passos por eles seguidos até a conclusão da atividade mostraram que para concluí-la a contento tiveram que recorrer tanto à literatura primária e secundária, quanto ao auxílio de colegas. Ou seja, o artigo científico os remeteu a vários outros textos e fontes. Além da internet, o uso de dicionários e de livros foi também constantemente mencionado:

(15) "Achei o meu artigo na Internet. Nunca tinha procurado pela Internet. Tive que aprender a procurar pelo portal CAPES".
(16) "Procurei pessoas que me ajudassem a entender o artigo. Do Instituto, da iniciação”.

(17) "Tive que usar dicionário, tradutor. Recorri a alguns livrostexto, porque o meu artigo está bem relacionado com a primeira matéria que nós vimos. Dei uma relida nos conceitos, só para entender melhor".

Para a realização da atividade proposta na disciplina de FísicoQuímica I os alunos apenas receberam a referência (nome da revista, ano, volume e página da publicação) com a qual iriam trabalhar e a incumbência de localizá-la. Não existiu uma preocupação em instruir os estudantes quanto às possíveis formas de localização da referência, uma vez que partimos do pressuposto de que os alunos, matriculados no quinto semestre do curso, já deveriam ser capazes de desempenhar esta tarefa por conta própria ou de procurar auxílio junto às bibliotecárias do campus, se assim o desejassem. Durante as discussões em grupo 56\% dos alunos disseram ter necessitado do auxílio de uma bibliotecária para localização do artigo e alguns afirmaram não conhecer as possíveis formas de localização de artigos via internet, existentes no Instituto de Química de São Carlos, até aquela data. Estes depoimentos sugerem a pouca destreza dos alunos frente a situações que envolvam a busca de referências, nas várias formas disponíveis atualmente. Suprir tal deficiência na formação dos estudantes de Química tem sido o objetivo de muitos educadores que descrevem a realização de atividades elaboradas com este intuito. Gallagher e Adams ${ }^{19}$, por ex., aplicaram uma estratégia de ensino em disciplina de Química Orgânica que visava apresentar a literatura, especialmente a literatura primária, na área de Química aos estudantes. Torná-los aptos a localizar artigos, via Chemical Abstracts, na versão impressa ou eletrônica, entre outras formas, fez-se necessário para que o objetivo fosse alcançado. Também com o intuito de minimizar esta deficiência, foram introduzidas no ano de 2004, na grade curricular do curso de Bacharelado em Química do Instituto de Química de São Carlos, disciplinas denominadas de Comunicação e Expressão em Linguagem Científica I e II. Para a abordagem de tópicos nelas contidos (como por ex., natureza da escrita em linguagem científica e recursos disponíveis para pesquisa bibliográfica em comunicações técnicas e científicas), atividades que exigem a busca e utilização de artigos científicos têm sido de grande valor.

\section{A avaliação da proposta}

Quando, para finalizar os trabalhos nos grupos de discussão, solicitamos aos alunos que avaliassem a proposta e apresentassem uma única justificativa capaz de fundamentar a emissão de um parecer positivo ou negativo sobre a mesma, 25 alunos avaliaram-na positivamente e 5 negativamente, conforme ilustra a Tabela 2 . Nesta tabela estão contidas as justificativas apresentadas e o número de vezes que cada uma delas foi citada pelos alunos. Cabe esclarecer que 3 alunos não apresentaram justificativa para a avaliação positiva que fizeram da proposta.

As informações presentes na Tabela 2 sugerem a boa aceitação da proposta, uma vez que foi avaliada positivamente por mais de $80 \%$ dos alunos. As duas justificativas mais freqüentemente citadas pelos estudantes para avaliar positivamente a proposta dizem respeito à sua capacidade de favorecer o entendimento dos conteúdos ministrados na disciplina em questão e a compreensão da aplicação destes conteúdos teóricos ministrados em sala. Algumas das justificativas apresentadas pelos estudantes indicam que o respaldo à proposta foi também oferecido com base nos vários benefícios que sua aplicação pode trazer à formação do bacharel em Química, no que tange a questões que não costumam ser plenamente contempladas 
Tabela 2. Justificativas apresentadas na avaliação da proposta de ensino e o número de vezes que cada uma delas foi citada pelos alunos

JUSTIFICATIVAS APRESENTADAS PARA EMISSÃO DE
PARECER POSITIVO SOBRE A PROPOSTA DE ENSINO
E O NÚMERO DE VEZES QUE CADA UMA DELAS
FOI CITADA PELOS ALUNOS

A atividade pode ajudar no cumprimento de tarefas relacionadas à iniciação científica A atividade pode ajudar a ampliar os horizontes de estudo do aluno

A atividade oferece a possibilidade de treinamento de uma 3 habilidade importante: a habilidade de leitura em inglês técnico A atividade oferece a possibilidade de treinamento de uma 4 habilidade importante: a habilidade de escrita A atividade pode facilitar o entendimento de conteúdos ministrados na disciplina em questão A atividade pode facilitar o entendimento da aplicação dos conteúdos ministrados na disciplina em questão
JUSTIFICATIVAS APRESENTADAS PARA EMISSÃO DE PARECER NEGATIVO SOBRE A PROPOSTA DE ENSINO E O NÚMERO DE VEZES QUE CADA UMA DELAS FOI CITADA PELOS ALUNOS

A atividade exige muito trabalho e tempo para a sua realização e o aprendizado não é significativo

2 A leitura de alguns textos é difícil e a ausência de 2 entendimento dos conteúdos neles apresentados pode não contribuir para o aprendizado do aluno

Nota: Três alunos avaliaram positivamente a proposta, sem apresentação de justificativa.

nas disciplinas formais, como o desenvolvimento da habilidade de expressão escrita e da capacidade de compreensão do inglês técnico. Alguns estudantes aprovaram a proposta pois nela encontraram componentes capazes de ampliar os seus horizontes de estudo e, também, de favorecer o desempenho de alunos de iniciação científica.

A avaliação negativa da proposta foi realizada pelos estudantes levando em conta o tempo necessário para o cumprimento de todas as suas etapas, que foi tido como excessivamente longo e pouco compensador, e a dificuldade encontrada na leitura de alguns textos, que impossibilitou a compreensão do assunto e o cumprimento da tarefa. Os aspectos levantados por estes alunos serão considerados na elaboração de uma nova versão da proposta de ensino. Tendo em vista estas observações, as questões que envolvem tempo e estabelecimento de critérios para escolha dos artigos serão tratadas com especial atenção.

De maneira geral, as justificativas apresentadas pelos alunos quando realizaram a avaliação da proposta estão em concordância com as percepções por eles expressas durante as discussões nos grupos. De fato, as justificativas que foram apresentadas com maior frequiência para a avaliação positiva da proposta ("A atividade pode facilitar o entendimento de conteúdos ministrados na disciplina em questão" e "A atividade pode facilitar o entendimento da aplicação dos conteúdos ministrados na disciplina em questão") também haviam sido mencionadas anteriormente por um número significativo de alunos. Em contrapartida, algumas justificativas ("A atividade pode ajudar no cumprimento de tarefas relacionadas à iniciação científica" e "A atividade pode ajudar a ampliar os horizontes de estudo do aluno") não haviam sido mencionadas durante as discussões nos grupos.

\section{CONSIDERAÇÕES FINAIS}

Propostas de ensino pautadas na utilização de artigos científicos têm sido aplicadas em cursos de graduação em Química nos últimos $\operatorname{anos}^{5,10,17,19-21}$. A proposta aqui descrita vem juntar-se a este rol de trabalhos, sendo possível, a partir da análise do processo de aplicação da mesma e das manifestações orais e escritas dos estudantes que dela participaram, tecer as seguintes considerações:

- embora a proposta tenha se concretizado na disciplina de FísicoQuímica I, pode ser adaptada a várias outras que compõem a grade curricular de cursos de Química, não exigindo a criação de uma disciplina específica para que possa ser levada a cabo. A condição primordial para a sua adoção é a existência de artigos científicos que apresentem de forma contextualizada conteúdos de Química contemplados nas disciplinas dos cursos regulares e que a forma de apresentação destes conteúdos esteja ao alcance do entendimento dos alunos. Esta condição pode ser atendida com maior ou menor facilidade, dependendo da disciplina em que se pretende trabalhar;

- algumas ponderações podem auxiliar àqueles que desejarem adotar a proposta aqui apresentada. A primeira delas diz respeito ao cuidado que se faz necessário na escolha dos artigos. Foi possível verificar que artigos que privilegiam temáticas que trazem no seu bojo a possibilidade de reflexão sobre aspectos não apenas científicos, mas também tecnológicos e sociais, foram comentados com maior entusiasmo pelos alunos. Da mesma forma, a extensão do artigo (número de páginas) também se constituiu em um fator de motivação, ou não, para o cumprimento da tarefa. Artigos com mais de cinco páginas exigiram um tempo de leitura maior que aquele que os alunos consideraram razoável. A segunda ponderação diz respeito ao tempo necessário para a aplicação da proposta e correção dos textos produzidos. O responsável pelo processo precisa estar ciente da exigência de várias horas de dedicação para a sua conclusão; não sendo incomum a abordagem dos alunos, tanto em sala de aula quanto fora dela, na busca de orientações que lhes proporcionem um melhor entendimento de aspectos citados no artigo científico;

- o cumprimento das tarefas componentes da proposta requer dedicação por parte dos alunos e os impele a assumir uma parcela considerável da responsabilidade pelo processo de aprendizagem, à medida que tende a tornar necessária a busca por fontes primárias e secundárias capazes de sanar dificuldades encontradas para a compreensão do artigo, principalmente aquelas relacionadas aos conceitos e métodos de Química embutidos nos artigos científicos;

- o fato de $33 \%$ dos alunos terem mencionado a possibilidade de identificação das correlações existentes entre o conteúdo da disciplina de Fisico-Química I e suas possíveis aplicações, via leitura do artigo científico, aponta para a utilização deste recurso como um caminho a ser considerado quando se pretende atingir tal objetivo;

- as dificuldades encontradas por $27 \%$ dos alunos na elaboração e escrita do resumo solicitado corroboram a observação feita por pesquisadores da área de Educação em Química sobre a necessidade de incorporação de atividades que visem desenvolver a habilidade de expressão escrita em cursos de graduação em Química; 
- a dificuldade apresentada por 56\% dos alunos, já em estágio avançado no curso de graduação, quando confrontados com a necessidade de localizar artigos científicos, sugere a urgência com que sejam feitas considerações sobre possíveis formas de introduzir a literatura em Química (e as formas de localização das informações desejadas) aos graduandos desta área. Propostas de ensino que fomentem a busca e leitura de artigos científicos surgem como alternativas possíveis.

Por fim, acreditamos que propostas curriculares que pensem na Química escolar trabalhando conceitos e exercícios, mas que também abarquem um maior leque de atividades que incluam a leitura e discussão/interpretação de artigos científicos (divulgação científica ou revisão, por ex.), podem encontrar receptividade entre graduandos em Química e trazer para a sala de aula a oportunidade de desenvolvimento de habilidades capazes de levar o aluno a um crescimento mais efetivo, não só quanto ao conhecer os fundamentos da disciplina, mas também quanto ao conhecer e desenvolver sua capacidade de comunicação, de trabalho em grupo e de pensamento crítico, que lhe favoreça o progresso profissional.

\section{AGRADECIMENTOS}

Ao suporte financeiro concedido pela FAPESP (Processo ${ }^{\circ}$ 03/ 06107-0), ao Prof. Dr. F. C. Nart (IQSC-USP) e aos alunos da disciplina SQF309 do IQSC - USP no primeiro semestre letivo de 2003.

\section{REFERÊNCIAS}

1. Cadernos Cedes 41, ano XVIII; Ensino da Ciência, Leitura e Literatura, UNICAMP/CEDES: Campinas, 1997.

2. Almeida, M. J. P. M.; Silva, H. C., orgs.; Linguagens, Leituras e Ensino da Ciência; Mercado de Letras: Campinas, 1998.

3. Almeida, M. J. P. M.; Silva, H. C., orgs.; Textos de Palestras e Sessões Temáticas: III Encontro Linguagens, Leituras e Ensino da Ciência; Graf. FE/UNICAMP: Campinas, 2000.

4. Queiroz, S. L.; Quim. Nova 2001, 24, 143.

5. Tilstra, L.; J. Chem. Educ. 2001, 78, 762.

6. White, H. B., III.; J. Coll. Sci. Teach. 2002, 31, 106

7. Herreid, C. F.; J. Coll. Sci. Teach. 1994, 23, 349.

8. Camill, P.; J. Coll. Sci. Teach. 2001, 30, 38 .

9. Houde, A.; J. Coll. Sci. Teach. 2002, 30, 184.

10. Rossi, F. M.; J. Chem. Educ. 1997, 74, 395.

11. Garrat, J.; Overton, T.; Educ. Chem. 1996, 33, 137.

12. Orlandi, E. P.; Interpretação: Autoria, Leituras e Efeitos do Trabalho Simbólico, Ed. Vozes: Petrópolis, 1996.

13. Barón, M.; J. Chem. Educ. 1989, 66, 1001.

14. McMillan, V. E.; Writing Papers in the Biological Sciences, Bedford Books: Boston, 1997.

15. Queiroz, S. L.; Almeida, M. J. P. M.; Ciênc. \& Educ. 2004, 10, 41.

16. Queiroz, S. L.; Almeida, M. J. P. M.; Book of Abstracts of $39^{\text {th }}$ IUPAC Congress and $86^{\text {th }}$ Conference of the Canadian Society for Chemistry, Ottawa, Canadá, 2003.

17. French, L. G. J.; J. Chem. Educ. 1992, 69, 287.

18. Janick-Buckner, D.; J. Coll. Sci. Teach. 1997, 27, 29.

19. Gallagher, G. J.; Adams, D. L.; J. Chem. Educ. 2002, 79, 1368.

20. Baldwin, M. J.; J. Chem. Educ. 2003, 80, 307.

21. Burness, J. H.; J. Chem. Educ. 1996, 73, 1120. 